Running Head: RECTIFYING SOCIAL INEQUALITIES

Rectifying Social Inequalities in a Resource Allocation Task

submitted to Cognition, March 17, 2016

revised and resubmitted June 28, 2016

Word Count: 10,190

(C) 2016. This manuscript version is made available under the Elsevier user license http://www.elsevier.com/open-access/userlicense/1.0/ 


\begin{abstract}
To investigate whether children rectify social inequalities in a resource allocation task, participants $(N=185$ African-American and European-American 5-6 year-olds and 10-11 yearolds) witnessed an inequality of school supplies between peers of different racial backgrounds. Assessments were conducted on how children judged the wrongfulness of the inequality, allocated new resources to racial ingroup and outgroup recipients, evaluated alternative allocation strategies, and reasoned about their decisions. Younger children showed ingroup favorability; their responses differed depending on whether they had witnessed their ingroup or an outgroup at a disadvantage. With age, children increasingly reasoned about the importance of equal access to school supplies and correcting past disparities. Older children judged the resource inequality negatively, allocated more resources to the disadvantaged group, and positively evaluated the actions of others who did the same, regardless of whether they had seen their racial ingroup or an outgroup at a disadvantage. Thus, balancing moral and social group concerns enabled individuals to rectify inequalities and ensure fair access to important resources regardless of racial group membership.
\end{abstract}

Key words: Social cognition; moral development; intergroup attitudes; fairness; ingroup bias; resource allocation 


\section{Rectifying Social Inequalities in a Resource Allocation Task}

\section{Introduction}

One of the pervasive conditions that leads to social inequality is when opportunities and resources are more available to certain social groups than to other social groups. The structure of most societies includes resource disparities along group lines (e.g., inequalities linked with race and gender) as well as social hierarchies which are bolstered by biases and negative assumptions about disadvantaged groups (Levy, West, \& Ramirez, 2005). Yet, at the same time, individuals are able to evaluate, critique, and sometimes even change inequalities that they deem to be unfair (Wainryb, Smetana, \& Turiel, 2008). In fact, while much of social life involves learning about and applying social norms and expectations, in many instances individuals recognize the importance of resisting unfair practices and challenging social inequities (Appiah, 2005; Nussbaum, 2001; Sen, 2009).

From early in life, children negatively evaluate the denial of resources (e.g., taking all the toys for oneself and leaving none for others) (see Smetana, Jambon, \& Ball, 2014). With age, children also recognize some circumstances under which it would be fair to allocate resources unequally, such as when one individual has worked harder and merits a greater reward (e.g., Baumard, Mascaro, \& Chevallier, 2012; Rizzo, Elenbaas, Cooley, \& Killen, 2016). But less research has examined how children conceptualize disadvantaged status regarding access to resources or recognize when it would be fair to rectify inequalities between groups (e.g., racial groups). Investigating the origins of concepts about social inequalities provides valuable insights into the factors that contribute to the decision to correct or perpetuate disadvantaged conditions. Such findings have the potential to contribute to the understanding of the cognitive processes involved in fairness judgments and prejudicial attitudes throughout childhood. 
To date, little research has investigated how children address resource inequalities when they are linked with group membership (e.g., race, ethnicity, gender), and only a handful of studies have extended beyond the allocation of small, desirable items like candy and toys to investigate children's responses to inequalities of resources with moral implications for recipients' wellbeing, including concerns for others' welfare. In order to address these questions, we examined children's reasoning, judgments, and behavior in response to an inequality of educational resources between groups of peers with different racial backgrounds (AfricanAmerican and European-American).

\subsection{Concerns for Fairness in Resource Allocation}

Children are aware of resource inequalities, both between themselves and others and between third parties, from early in life. For example, young children share resources equally with collaborators (Melis, Altrichter, \& Tomasello, 2013; Warneken, Lohse, Melis, \& Tomasello, 2011) and reject unequal allocations that favor a partner over themselves (Blake et al., 2015). By 8-10 years of age, children also reject unequal allocations that favor themselves over a partner (Blake \& McAuliffe, 2011; Fehr, Bernhard, \& Rockenbach, 2008) or one recipient over another (Shaw \& Olson, 2012) when both parties are equally deserving of resources.

Young children seek to equalize resource distributions between others, allocating limited resources to disadvantaged individuals, even when they do not stand to gain by acquiring resources for themselves. For example, young children correct inequalities between third parties by allocating more items to a recipient with fewer resources (Li, Spitzer, \& Olson, 2014; Paulus, 2014), and this corrective approach increases with age. That is, later in childhood, children choose to allocate based on need (in order to correct inequalities) even when they could distribute equally. By 8 years of age, children prefer to rectify inequalities between recipients (by 
giving more to a disadvantaged individual) rather than dividing items strictly equally (Kienbaum \& Wilkening, 2009; Rizzo \& Killen, 2016; Schmidt, Svetlova, Johe, \& Tomasello, 2016; Shaw \& Olson, 2013). Thus, with age, children are increasingly capable of weighing and prioritizing complex moral claims to resources, often choosing to correct inequalities between individuals when they have the opportunity to distribute resources.

\subsection{Concerns for Group Membership in Resource Allocation}

The studies introduced above highlight the early emergence and continued development of children's consideration of moral concerns when allocating resources. In intergroup contexts, however, additional group-related concerns can also influence children's resource allocation decisions, including issues of prejudice, discrimination, and bias. For instance, young children sometimes allocate more resources like candy and toys to members of their own racial, gender, and minimal ingroup than to outgroup members (Benozio \& Diesendruck, 2015; Dunham, Baron, \& Carey, 2011; Moore, 2009; Renno \& Shutts, 2015). This type of differential allocation based on group membership is a form of ingroup bias. Likewise, older children have been shown to allocate resources preferentially based on group membership (Gummerum, Takezawa, \& Keller, 2009), and to use group stereotypes to justify differential resource allocation (McGillicuddy-De Lisi, Daly, \& Neal, 2006).

\subsection{Social Inequality and Resource Allocation}

In particular, research on children's allocation decisions in light of between-group (or intergroup) resource disparities is necessary for understanding how allocation decisions bear on social inequalities. As an illustration, Olson, Dweck, Spelke, and Banaji (2011) tested whether children from 3-11 years of age perpetuated or rectified an inequality of cookies between recipients from different racial groups. Children most often adhered to the status quo, giving 
more cookies to the recipient from the racial group that they had seen receiving more cookies. Similar work indicates that observation of a resource inequality between racial groups or novel groups can lead children to assume that the disparity is legitimate or deserved, and to perpetuate it themselves by allocating more goods to a member of an advantaged group (Horwitz, Shutts, \& Olson, 2014; Li et al., 2014). Likewise, some research shows that young children are more likely to reject resource inequalities that disadvantage their minimal ingroup than inequalities that disadvantage their minimal outgroup (Jordan, McAuliffe, \& Warneken, 2014).

Further, the role of intergroup biases in children's reasoning about the distribution of resources that pertain to others' welfare (e.g., educational needs) remains relatively unexplored. The distribution of educational resources is one that is relevant for group-level analysis given that societal patterns of inequality in access to quality education based on group membership, including racial group membership, remain pervasive (Duncan \& Murnane, 2011). When faced with an inequality of educational resources between peers of different racial backgrounds, one possibility is that children will perpetuate the status quo inequality by allocating more resources to an advantaged group (more to the group that already has more), particularly if they identify with the advantaged group. The studies described above would support this prediction. Alternatively, children may demonstrate increasing concern for fairness and others' welfare with age, choosing to distribute in a way that corrects the inequality.

Supporting this second possibility, one recent study found that, by 8 years of age, children distinguish between resources described as luxuries and resources described as necessities in a merit-based allocation context. In this study, children allocated luxury resources meritoriously (more to the hard working character), and allocated necessary resources equally, based on a concern for recipients' welfare (Rizzo et al., 2016). This study, however, did not have 
an intergroup component. Given that children begin to endorse their own and others' equal rights to quality education by early adolescence (Peterson-Badali, Morine, Ruck, \& Slonim, 2004), and negatively judge denial of access to education (Brown, 2006; Helwig \& Jasiobedzka, 2001), it is likely that older children will perceive an inequality of educational resources as highly detrimental for the disadvantaged group, potentially overcoming ingroup biases in favor of corrective action when differential resource allocation would cause harm to disadvantaged parties.

Further, there is some evidence that older African-American children and adolescents are more perceptive of discrimination in various social contexts than their European-American peers (Brown, Alabi, Huynh, \& Masten, 2011; McKown \& Weinstein, 2003; McKown, 2004). This suggests that older African-American children may be more likely than older EuropeanAmerican children to perceive an inequality of resources between peers of different racial backgrounds as wrong, and to support corrective action. To date, most studies of children's differential resource allocation to racial ingroup versus outgroup members and of children's corrective actions in light of a pre-existing resource inequality have been conducted with predominantly European-American samples. Thus, it is an open question whether AfricanAmerican children may be more supportive of corrective action in light of an intergroup inequality of educational resources compared to their European-American peers.

\subsection{Social Reasoning Developmental Model}

As outlined above, children must navigate potentially competing concerns for fairness and group membership in intergroup resource allocation contexts. That is, children must balance moral concerns regarding the treatment of others (fairness and others' welfare) with social group 
concerns regarding the treatment of others based on their ingroup or outgroup membership (Killen, Elenbaas, Rizzo, \& Rutland, 2016).

In order to frame the current study, we drew on an integrative theoretical model called the social reasoning developmental (SRD) model, which emphasizes the importance of both moral concerns about fairness and justice as well as group affiliations and expectations throughout development (Killen, Elenbaas, \& Rutland, 2015; Rutland, Killen, \& Abrams, 2010). This theoretical model draws on extensive work on moral development from the perspective of social domain theory as well as developmental social identity theories concerning intergroup attitudes. Social domain theory has identified different categories of reasoning (moral, societal, and psychological) that individuals use when evaluating social events (Smetana et al., 2014; Turiel, 2006). Moral knowledge refers to judgments about fairness, equality, and rights; societal knowledge refers to customs and traditions that promote group functioning both within and between groups; psychological knowledge refers to judgments about personal choice and autonomy. Developmental social identity theories chart the developmental onset of ingroup bias and outgroup dislike for understanding the origins of prejudice and discrimination (Abrams \& Rutland, 2008; Nesdale, 2004; Verkuyten, 2007).

Many studies at the intersection of resource allocation and intergroup attitudes have focused on the negative aspects of group membership (e.g., ingroup biases, prejudice). The SRD model, likewise, holds that group membership and group identity constitute a fundamental factor in children's reasoning about resource allocation (Killen et al., 2016). However, this model takes a more nuanced view about the potential role of group knowledge and intergroup relations in children's judgments, reasoning, and decisions in allocation contexts. Contrary to the findings from research described above in which ingroup concerns distract from concerns for fairness, 
recent research drawing on this model indicates that, in some cases, awareness or knowledge about groups and intergroup relations (a type of societal knowledge) can contribute to, rather than impede, the promotion of fairness (moral knowledge) in childhood. For example, with age, children increasingly support individuals who advocate for fair allocation of resources in an intergroup context even if it means that their group receives less of a valued resource.

Specifically, while older children recognize that groups would prefer to receive more resources for their ingroup, they themselves personally deem equality between groups to be the fairest distribution (Cooley \& Killen, 2015; Mulvey, Hitti, Rutland, Abrams, \& Killen, 2014).

Thus, with age, children gain increasing social awareness about how groups function (Abrams \& Rutland, 2008). At the same time, they develop moral judgments about the fair way to distribute resources between groups, taking others' needs into account (Killen \& Smetana, 2015). Less is known, however, about children's judgments and reasoning in resource allocation contexts when recipient groups have received different amounts of resources in the past, and do not share the same group membership. In a context like this, consideration of group membership is essential for achieving a fair allocation. Ignoring recipient group membership in this type of context would mean ignoring a history of unfair allocation between groups. The SRD model would predict that, with age, when children have knowledge about unfair intergroup relations in the past, they can use that knowledge to advocate for fair allocation between groups in the present.

\subsection{The Current Study}

In the current study, we tested these questions by measuring children's judgments, reasoning, and behavior in response to an inequality of educational resources between peers of different racial backgrounds. That is, extending recent research drawing on the SRD model, we 
examined how children weighed moral concerns about fairness with group affiliations when responding to intergroup resource inequality. In order to understand whether children rectify social inequalities in a resource allocation paradigm, we examined African-American and European-American children's reasoning, judgments, and behavior in response to an inequality of resources that affected their racial ingroup and an outgroup.

We tested these questions with a sample of 5-6 and 10-11 year-olds because research from the SRD perspective (Horn, 2003; Mulvey et al., 2014; Rizzo et al., 2016) as well as related work (Brown, 2006; Helwig \& Jasiobedzka, 2001; Peterson-Badali et al., 2004) has demonstrated that understanding of the broader implications of an inequality of important resources (i.e., educational supplies) emerges and develops during this age span. To date, however, less is known about how children choose to distribute educational resources in a context of pre-existing intergroup inequality. Judging the denial of important resources as detrimental for individuals is different from actively allocating resources in a context of intergroup inequality, and this distinction has moral implications. The former judgment entails a negative evaluation of a situation in which needs are not met, whereas the latter response requires children to weigh fairness and group concerns to determine the best course of action in such a context. That is, actively allocating resources to rectify a pre-existing intergroup inequality may be more difficult for children than simply recognizing that the inequality is unfair. Whether children allocate resources in order to rectify intergroup inequalities was a central focus of the present study.

Another important dimension of the current study was the inclusion of both AfricanAmerican and European-American participants (from similar socioeconomic backgrounds). Because less is known about the resource allocation decisions of African-American children in 
intergroup contexts, it is yet unclear whether potential group biases (e.g., preferential allocation to one's racial ingroup) would emerge among children from both racial backgrounds, as has been shown for European-American children (e.g., Renno \& Shutts, 2015), or whether AfricanAmerican children, like African-American adolescents (e.g., Brown et al., 2011), would demonstrate increased recognition of discrimination leading to a potential increased support for rectifying inequalities.

To assess these questions, European-American and African-American kindergartners (5-6 years of age) and fifth graders (10-11 years of age) in the current study witnessed an inequality of school supplies in which schools serving students of one racial group received fewer supplies than schools serving students of another racial group. Half of the participant sample viewed their racial ingroup receiving fewer supplies than an outgroup, and the other half of the sample saw the outgroup receiving fewer supplies than their ingroup. Thus, the experimental design was balanced by participant and target race. Participants were asked to make a judgment about the wrongfulness of the inequality and give a justification for their decision, allocate school supplies and give a justification for their decision, and evaluate others' decisions to perpetuate or rectify the inequality. The use of multiple measures (judgments, allocations, and verbal reasoning) allowed for an analysis of our research questions from several angles and more robust conclusions regarding age-related changes in children's responses to inequality. Using multiple measures helps alleviate concerns that assessing only behavior or only judgments misses part of the developmental picture.

\subsection{Hypotheses}

In line with the SRD model (Killen et al., 2015; Rutland et al., 2010), we expected that children's responses to inequality would reflect moral concerns for fairness as well as social 
considerations of the intergroup context. We also predicted age-related changes in children's ability to balance moral and social group concerns. Fairness does not always entail strict impartiality or disregard for group factors. Thus, this study tested an important prediction of the SRD model; with age, children would recognize that ensuring a fair allocation requires knowledge about intergroup relations, such as the consideration of the past history of inequality between groups.

Our first set of hypotheses (H1) pertained to younger children's responses across the range of measures. We predicted that (H1) younger children (5-6 year-olds) who witnessed their racial ingroup receiving fewer supplies would judge the inequality to be more wrong than young children who witnessed the outgroup receiving fewer supplies. Likewise younger children who witnessed their racial ingroup at a disadvantage would be more likely to rectify the inequality than younger children who witnessed the outgroup receiving fewer supplies. And finally, younger children who witnessed their racial ingroup receiving fewer supplies would evaluate others' decisions to give more to the outgroup as less acceptable and more to the ingroup as more acceptable relative to young children who witnessed the outgroup at a disadvantage.

In intergroup contexts, when children must balance fairness concerns with group affiliations, younger children are more likely to show racial biases (McGlothlin \& Killen, 2006). Related work also indicates that the needs of the ingroup are particularly salient for young children (Weller \& Lagattuta, 2013). Importantly, however, we did not predict across-the-board ingroup bias among 5-6 year-olds. Rather, in this context of pre-existing inequality, we hypothesized that 5-6 year-olds would demonstrate a different form of differential treatment by attending more explicitly to an inequality that put their ingroup at a disadvantage than to an inequality that put the outgroup at a disadvantage. 
Our second set of hypotheses $(\mathrm{H} 2)$ pertained to older children's responses across the range of measures. We predicted that $(\mathrm{H} 2)$ older children (10-11 year-olds) would not differ significantly in their judgments of the inequality, their allocation decisions, or their evaluations of others' decisions to perpetuate or rectify the inequality as a function of whether they had witnessed their racial ingroup or the outgroup receiving fewer school supplies. This hypothesis was based on research from the SRD perspective indicating that, with age, children support fair allocation, even when their group could benefit from inequality (Mulvey et al., 2014), and support fair access to resources that have important implications for recipients' wellbeing (Rizzo et al., 2016). This does not mean that older children would find racial group membership or intergroup relations irrelevant to their decisions. Rather, we predicted that 10-11 year-olds would perceive an inequality of school supplies to be highly detrimental for the disadvantaged group (Brown, 2006; Helwig \& Jasiobedzka, 2001), overcoming ingroup biases in support of corrective action.

Our third set of hypotheses (H3) pertained to the age-related changes in children's reasoning for their decisions that we hypothesized would underlie these age-related changes in judgments and behavior. We predicted that, with age, children would (H3) increasingly justify their evaluations of the inequality with reference to the need to ensure equal access to resources (particularly among children who judged the inequality as "not okay") and would increasingly justify their allocation decisions with reference to the need to correct previous inequalities. Thus, H3 pertained to children's increasing awareness that educational resources should be allocated equally between groups (Peterson-Badali et al., 2004), and if they have not been allocated equally in the past, corrective action is needed to address the inequality (Kienbaum \& Wilkening, 2009). 
Notably, it was an open question as to whether African-American children would be more likely than European-American children to rectify the resource inequality. Some research indicates that older African-American children and adolescents are more perceptive of discrimination than are their European-American peers (Brown et al., 2011; McKown \& Weinstein, 2003; McKown, 2004). In the current study, however, the resource inequality between groups was evident. Recognizing that the disparity was linked to race did not require an extra inference or sensitivity to subtle behavioral cues, which previous work suggests may have been interpreted more readily by African-American children. Previous work also indicates that both European-American and African-American children are concerned about fairness when access to education has been restricted based on group membership (e.g., Killen, Lee-Kim, McGlothlin, \& Stangor, 2002). Thus, participant race was an important variable for this study. In order to test our hypotheses about younger children's differential responses based on whether they witnessed their racial ingroup or an outgroup at a disadvantage (as outlined in $\mathrm{H} 1$ above), we included a balanced sample with both African-American and European-American participants.

\section{Materials and Methods}

\subsection{Participants}

Children in kindergarten ( $n=91 ; 5-6$ years, $M=5.96$ years, $S D=.34$ years $)$ and fifth grade $(n=94 ; 10-11$ years, $M=11.10$ years, $S D=.65$ years $)$ participated $(N=185)$. The sample was approximately evenly divided by gender (46 male and 45 female kindergartners; 42 male and 52 female fifth graders) and by race (43 African-American and 48 European-American kindergartners; 50 African-American and 44 European-American fifth graders). Participants were recruited from eight racially diverse elementary schools serving the same socioeconomic 
communities: middle- to low-middle-income families in the Mid-Atlantic region of the United States. No information on individual parental educational attainment or income level was available. Across all schools, the racial composition of the school population was diverse; no schools had less than 20\% African-American nor more than 50\% European-American students. The average parental consent response rate across schools was approximately $70 \%$. Written parental consent and children's verbal assent were obtained for all participants.

\subsection{Procedure}

All participants were seated in front of a laptop where they completed the assessments. All stimuli and measures were presented using MediaLab v2012 (Empirisoft Corporation). The entire experimental session was conducted in quiet spaces at participants' schools and took approximately 25 minutes. Older children completed measures independently while a trained experimenter interviewed younger children. Pilot testing was conducted prior to data collection to ensure that the youngest participants would be able to follow the procedure, remain engaged, and complete the range of assessments. This pilot testing also indicated no differences in responses as a function of whether children viewed the stimuli and questions on their own or with an experimenter. To determine whether the resources depicted were viewed as important by participants, before viewing the experimental inequality and responding to the target questions (as described below) each child was shown a picture of a box of school supplies containing the same supplies used in the experimental manipulation (books, calculators, art materials, and notebooks), and asked “Are these important for kids to have?" Response options were "yes" or "no". The vast majority (97\%) of participants viewed school supplies as something that was “important for kids to have," confirming that school supplies were viewed as an important resource. 


\subsection{Measures}

2.3.1 Experimental inequality. Participants witnessed four pairings of racial group membership and distribution of school supplies. For each pairing, the following appeared on the laptop screen: two photographs of prototypic school buildings, two groups of four children's photographs (aged 5-11 years, evenly divided by gender), and the words "These are two schools in the same city. There are the same number of kids who go to both schools. Here are some of the kids who go to this school. And here are some of the kids who go to this school." One group of children depicted was African-American, and one group was European-American. Next, six boxes of school supplies (photographs superimposed on images of standard brown cardboard boxes) and the words "In these kids' school, every classroom has six boxes of $[\mathrm{X}]$ to use when the kids are learning" appeared under one group of children, and one box of school supplies and the words "In these kids' school, every classroom has one box of [X] to use when the kids are learning" appeared under the other group. Supplies were presented in a fixed order across the four trials: books, calculators, art materials, and notebooks.

Participants viewed different school buildings and groups of children across all four trials, but the number of boxes of supplies associated with each racial group varied systematically. Half of the participants witnessed the African-American groups receiving fewer school supplies, and half of the participants witnessed the European-American groups receiving fewer school supplies. Assignment to context was randomized across participants; the side of the screen on which each racial group appeared was counterbalanced across the four pairings.

2.3.2 Inequality Judgment Task. A four-point smiley face rating scale appeared on the screen next to the pictures of the schools and supplies, accompanied by the question "How okay or not okay is it that these schools have more supplies than these schools?" Children indicated 
their judgment by pointing to or clicking one of the buttons corresponding to each point on the scale: 1 = "really not okay" to 4 = "really okay". Following their judgment, justifications were assessed: "Why do you think it's [X]?" Older children provided a justification by typing directly into a free response field, and younger children dictated their response to the experimenter.

2.3.3 Resource Allocation Task. After the Inequality Judgment Task, the following appeared on the laptop screen: two photographs of schools and groups of children (age and gender controlled in the same manner as the experimental inequality), seven boxes of school supplies, and the question "If you were in charge of a city and you had seven boxes of school supplies to give out, how should you give them out between these two schools?" One group of children was African-American, and one group was European-American. The boxes of school supplies contained all four supplies previously viewed (books, calculators, art materials, and notebooks). Next, eight buttons with numbers appeared on the screen, representing all of the possible divisions of the seven boxes of school supplies between the two schools. Children allocated resources by pointing to or clicking one of the corresponding buttons. Following their allocation, justifications were assessed: "Why did you give [X] boxes to this school and [Y] boxes to this school?" As before, older children provided a justification by typing directly into a free response field, and younger children dictated their response to the experimenter.

2.3.4 Strategy Evaluation Task. Next, the same two photographs of schools and groups of children reappeared on the screen, accompanied by the same four-point smiley face rating scale of acceptability described previously. In regards to the school representing the racial group that had received more resources, children were asked: "What if the person in charge of the city gave more boxes to this school because they always got more before? How okay or not okay would that be?" Then in regards to the school representing the racial group that had received 
fewer resources, children were asked: "What if the person in charge of the city gave more boxes to this school because they always got less before? How okay or not okay would that be?" For both measures, children indicated their evaluation of the strategy by pointing to or clicking one of the buttons corresponding to each of the four points on the scale.

\subsection{Coding of open-ended justifications}

Children's open-ended justifications for their judgments and allocations were coded for analyses into one of four conceptual categories expected based on previous research (Cooley \& Killen, 2015; Mulvey et al., 2014; Rizzo et al., 2016): 1) Past Inequality, 2) Equality, 3) Status Quo, and 4) Personal Preferences. Past Inequality justifications pertained to some schools having received more or less than others in the past (e.g., "That's not fair because they had less and the others had more", "They didn't have more before so I'm giving them more now"). Equality justifications were based on the premise that all schools should have equal supplies (e.g., "Both schools should have the same amount of supplies for learning", "Because then it would be closest to even and it would be fair"). Status Quo justifications referred to the observed status quo or allocation witnessed (e.g., "The kids might need more supplies then because it takes more for them to learn", "I noticed that they always get more and they always get less"). Personal Preferences was defined in terms of participant's own preferences or desires (e.g., "I just want to"). Open-ended justifications that did not fit into one of these categories were coded as "other". The content coding of justifications was conducted by two coders blind to the hypotheses of the study. On the basis of $25 \%$ of the data ( $n=47$ participants), Cohen's $\kappa=.85$ was computed for inter-rater reliability.

\section{Results}

\subsection{Judgments of the Resource Inequality and Justifications for Judgments}


3.1.1 Inequality judgments. The majority of children (78\%) judged the school supply inequality negatively (as "not okay" or "really not okay"), with $22 \%$ judging it "okay" or "really okay". In order to test our hypotheses pertaining to differences in children's judgments by age and by which group they had seen receiving fewer resources (H1 and H2), we conducted a 2 (Age: 5-6 years, 10-11 years) x 2 (Race: African-American, European-American), x 2 (Group Received Fewer Supplies: Ingroup, Outgroup) ANOVA for children's ratings of the resource inequality. This revealed a main effect for Age, $F(1,176)=18.42 p<.001 \eta_{\mathrm{p}}{ }^{2}=.10$; older children $(M=1.52, S D=.77)$ judged the inequality more negatively than did younger children $(M=2.10, S D=1.08)$, as well as an interaction effect for Age x Group Received Fewer Supplies, $F(1,176)=3.96 p=.04 \eta_{\mathrm{p}}{ }^{2}=.02$, which was followed up using pairwise comparisons with Bonferroni correction for multiple comparisons.

As hypothesized, younger children judged the inequality as more acceptable when they had seen the outgroup receiving fewer supplies $(M=2.37, S D=1.05)$ than when they had seen their racial ingroup receiving fewer supplies $(M=1.83, S D=1.05), p=.006$; but older children's judgments did not differ significantly based on whether they had seen the outgroup $(M=1.51$, $S D=.69)$ or their ingroup $(M=1.55, S D=.84)$ receiving fewer supplies, $p=.98$. Further, older children who had seen the outgroup receiving fewer supplies judged the inequality more negatively than younger children who had seen the outgroup receiving fewer supplies, $p<.001$; but judgments did not differ significantly by age for children who had seen their ingroup receiving fewer supplies, $p=.10$.

Next, we conducted chi square tests for the same hypotheses (H1 and H2) with children's judgments dichotomized to "not okay" versus "okay". This enabled us to test for differences in the proportion of children judging the inequality to be acceptable ("okay" or "really okay") 
versus unacceptable ("not okay" or "really not okay") by age and by which group had received fewer supplies (ingroup or outgroup). These models replicated the main effect for Age and the interaction for Age x Group Received Fewer Supplies reported in the ANOVA above (see Figure 1).

A greater proportion of older children (87\%) than younger children $(69 \%)$ judged the inequality to be "not okay", $\chi^{2}(1, N=184)=9.10, p=.003$. Further, the proportion of younger children who judged the inequality negatively differed significantly by whether they had seen their racial ingroup or the outgroup receiving fewer supplies. A majority (79\%), of younger children who witnessed their ingroup at a disadvantage judged the inequality negatively, in contrast to $58 \%$ of younger children who witnessed the outgroup at a disadvantage, $\chi^{2}(1, N=$ $90)=4.44, p=.04$. The proportion of older children judging the inequality negatively did not differ significantly by which group had received fewer supplies; $86 \%$ of older children who witnessed their ingroup at a disadvantaged judged the inequality negatively, and $89 \%$ of older children who witnessed the outgroup at a disadvantage did the same, $\chi^{2}(1, N=94)=.21, p=$ .65. Likewise paralleling the ANOVA results, among children who had seen the outgroup receiving fewer supplies, a greater proportion of older children (89\%) than younger children $(58 \%)$ judged the inequality negatively $(89 \%), \chi^{2}(1, N=88)=10.77, p=.001$; but among children who had seen the ingroup receiving fewer supplies, the proportion judging the inequality negatively did not differ significantly by age (79\% of younger children versus $86 \%$ of older children), $\chi^{2}(1, N=96)=.81, p=.37$. 


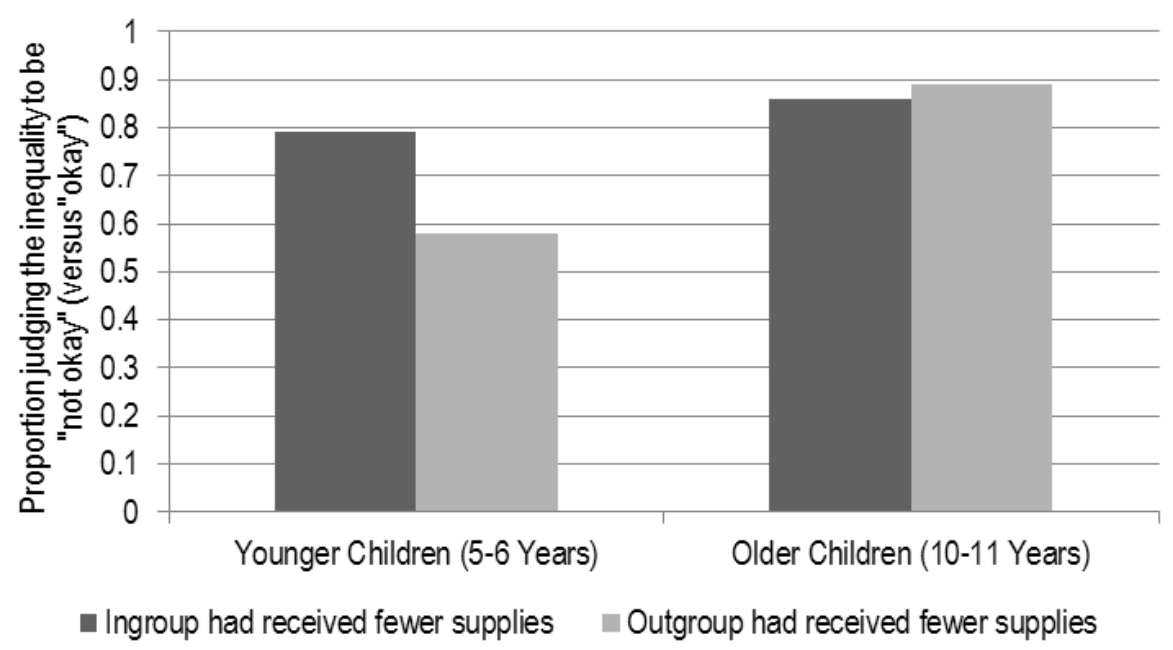

Figure 1. Proportion of children who judged the school supply inequality negatively, by age and by which group they had observed receiving fewer supplies.

Thus, 5-6 year-olds who witnessed their racial ingroup receiving fewer supplies judged the inequality to be more wrong than 5-6 year-olds who witnessed the outgroup receiving fewer supplies, but 10-11 year-olds' negative judgments of school supply inequalities did not differ significantly based on which group was receiving fewer resources. Next we examined children's reasoning for their judgments in order to understand these age-related changes.

3.1.2 Justifications for inequality judgments. As noted above, children's justifications were coded into one of four conceptual categories based on previous research findings and pilot data for the current study. Children most frequently justified their judgments of the school supply inequality with references to Past Inequality (47\% of children) or to Equality (29\% of children). An additional 14\% of children referenced Status Quo, 7\% referenced Personal Preferences, and only $3 \%$ were unable to justify their judgment.

In order to test our hypotheses regarding age-related changes in children's reasoning about their judgments (H3), we conducted a 2 (Age: 5-6 years, 10-11 years) x 2 (Judgment: Okay 
Not Okay) x 5 (Justification) chi square test of independence. The overall test was significant, $\chi^{2}$ $(4, N=184)=25.52, p<.001$. Follow-up z-tests with Bonferroni correction for multiple comparisons indicated that $(\mathrm{H} 3)$ older children referenced Equality more frequently than younger children. Interestingly, older children also referenced Personal Preferences less frequently than younger children. References to Past Inequality and Status Quo (e.g., "The kids might need more supplies because it takes more for them to learn") did not differ significantly by age. All differences reported were significant at $p<.05$.

Further, age-related changes in children's justifications were significant among children who judged the inequality as "not okay", $\chi^{2}(4, N=144)=12.12, p=.004$, and among children who judged the inequality as "okay", $\chi^{2}(2, N=40)=7.26, p=.03$. Among children who judged the inequality as "not okay", older children referenced Equality (e.g., "Both schools should have the same amount of supplies for learning") more frequently than younger children, and referenced Past Inequality (e.g., "That's not fair because they had less and the others had more") less frequently than younger children. References to Status Quo and Personal Preferences did not differ significantly by age among children who judged the inequality as "not okay." All differences reported were significant at $p<.05$; see Table 1 for all proportions.

Among children who judged the inequality as "okay", older children referenced Status Quo (e.g., "The kids might need more supplies because it takes more for them to learn") more frequently than younger children. References to Personal Preferences did not differ significantly by age among children who judged the inequality as "okay". No children who judged the inequality as "okay" referenced Equality or Past Inequality. All differences reported were significant at $p<.05$; see Table 1 for all proportions. 
Table 1.

Children's Justifications for their Judgment of the School Supply Inequality, by Age Group and Judgment

\begin{tabular}{|c|c|c|c|c|c|c|c|c|}
\hline & \multicolumn{4}{|c|}{ Judgment: "Not Okay" } & \multicolumn{4}{|c|}{ Judgment: “Okay" } \\
\hline & \multicolumn{2}{|c|}{$\begin{array}{l}\text { Younger Children } \\
\text { (5-6 Years) }\end{array}$} & \multicolumn{2}{|c|}{$\begin{array}{c}\text { Older Children } \\
\text { (10-11 Years) }\end{array}$} & \multicolumn{2}{|c|}{$\begin{array}{l}\text { Younger Children } \\
\text { (5-6 Years) }\end{array}$} & \multicolumn{2}{|c|}{$\begin{array}{c}\text { Older Children } \\
\text { (10-11 Years) }\end{array}$} \\
\hline & Proportion & $n$ & Proportion & $n$ & Proportion & $n$ & Proportion & $n$ \\
\hline $\begin{array}{l}\text { Past } \\
\text { Inequality }\end{array}$ & $.69^{a}$ & 43 & $.52^{a}$ & 43 & 0 & 0 & 0 & 0 \\
\hline Equality & $.24^{b}$ & 15 & $.48^{b}$ & 39 & 0 & 0 & 0 & 0 \\
\hline Status Quo & .03 & 2 & 0 & 0 & $.46^{c}$ & 13 & $.92^{c}$ & 11 \\
\hline $\begin{array}{l}\text { Personal } \\
\text { Preferences }\end{array}$ & .02 & 1 & 0 & 0 & .39 & 11 & .08 & 1 \\
\hline Other & .02 & 1 & 0 & 0 & .14 & 4 & 0 & 0 \\
\hline
\end{tabular}

Note. $a, b$, and $c$ denote column proportions that differ significantly from each other at $p<.05$.

Children's justifications for their judgments did not vary significantly by race, $\chi^{2}(4, N=$ 184) $=4.99, p=.29$, or by whether the participant had seen their ingroup or the outgroup receiving fewer supplies, $\chi^{2}(4, N=184)=5.74, p=.23$. Additionally, a 2 (Age: 5-6 years, 10 11 years) x 2 (Group Received Fewer Supplies: Ingroup, Outgroup) x 5 (Justification) chi square test of independence revealed no significant differences in children's justifications at 5-6 years, $\chi^{2}(4, N=90)=8.87, p=.06$, or at $10-11$ years, $\chi^{2}(4, N=94)=1.91, p=.59$, based on whether children had seen their racial ingroup or the outgroup receiving fewer supplies.

Children's justifications helped to explain the age-related changes in their judgments of the school supply inequality. With age, children who judged the inequality negatively increasingly referenced the importance of equal access to school supplies. Thus, older children 
judged the inequality as more wrong (regardless of whether their racial ingroup or the outgroup was disadvantaged) largely out of concern for groups' equal access to educational supplies.

\subsection{Resource Allocation Decisions and Justifications for Allocations}

3.2.1 Resource allocation decisions. To test our hypotheses regarding differences in children's resource allocation decisions by age and by which group they had seen receiving fewer resources (H1 and H2), we conducted a 2 (Age: 5-6 years, 10-11 years) x 2 (Race: African-American, European-American), x 2 (Group Received Fewer Supplies: Ingroup, Outgroup) ANOVA for children's allocation of supplies to the school representing the group that had received fewer supplies. This revealed no main effects or interaction effects. However, we hypothesized certain circumstances under which children would be expected to allocate more resources to the disadvantaged racial group (that they had seen receiving fewer resources), and certain circumstances under which children would not be expected to rectify the inequality.

To test these hypotheses, we conducted chi square tests with children's allocation decisions dichotomized to "more to disadvantaged" versus "more to advantaged". This enabled us to test for differences in the proportion of children rectifying the inequality by age and by which group they had seen receiving fewer supplies (ingroup or outgroup), see Figure 2. These models revealed a main effect for which group had received fewer supplies (ingroup or outgroup), as well as an interaction effect for Age x Group Received Fewer Supplies.

A greater proportion of children who saw their ingroup at a disadvantage (73\%) rectified the inequality than children who saw the outgroup at a disadvantage $(54 \%$ rectified $), \chi^{2}(1, N=$ $181)=6.92, p=.009$. The proportion of younger children who rectified the inequality (by giving more resources to the disadvantaged group) differed significantly by whether they had seen their ingroup or their outgroup receiving fewer supplies. The majority $(70 \%)$ of younger children who 
witnessed their ingroup at a disadvantage rectified the inequality, versus a minority (44\%) of younger children who witnessed the outgroup at a disadvantage, $\chi^{2}(1, N=90)=6.24, p=.01$. The proportion of older children rectifying the inequality did not differ significantly by which group had received fewer supplies; $76 \%$ of older children who witnessed their ingroup at a disadvantaged rectified the inequality, and $64 \%$ of older children who witnessed the outgroup at a disadvantage did the same, $\chi^{2}(1, N=91)=1.37, p=.24$.

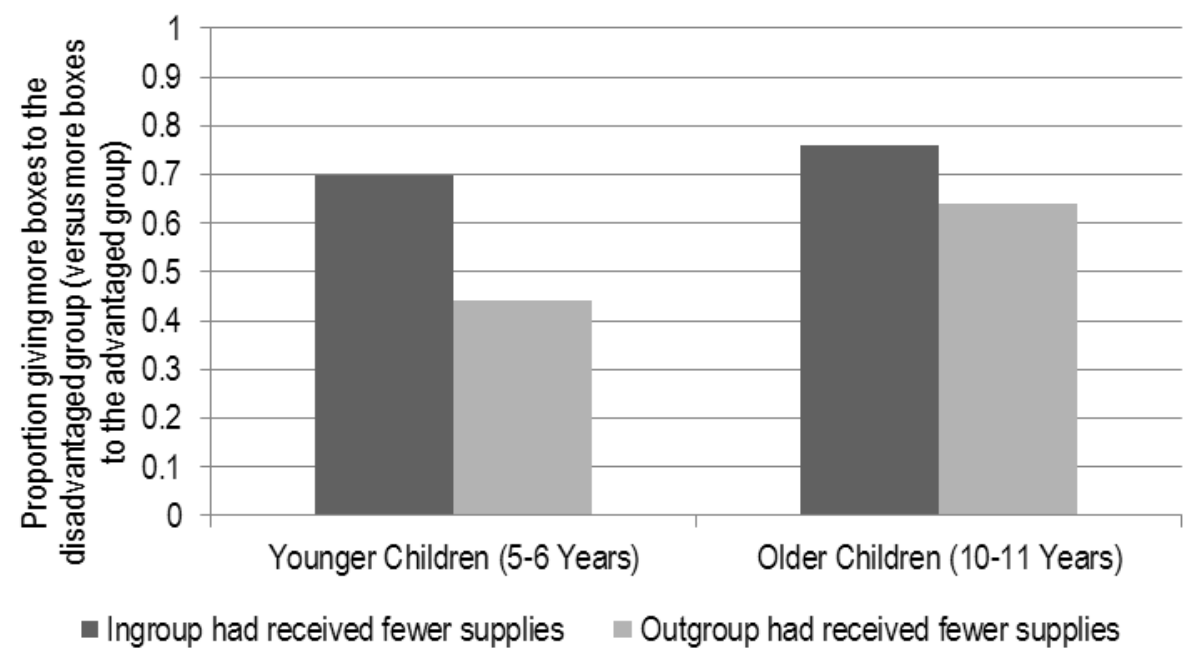

Figure 2. Proportion of children who rectified the school supply inequality by giving more supplies to the disadvantaged group, by age and by which group they had observed receiving fewer supplies.

Similar to the findings on younger children's judgments of the inequality (above), 5-6 year-olds were more likely to correct the inequality when their racial ingroup had been receiving fewer resources than when the outgroup had been receiving fewer resources. Older children's decisions to rectify the inequality, by contrast, did not differ significantly by which group was 
disadvantaged. We turned to children's justifications for their allocation decisions to illuminate these age-related changes.

3.2.2 Justifications for resource allocation decisions. Children's justifications were coded into one of four conceptual categories. Among these, children most frequently justified their resource allocation decision with references to Equality $(35 \%, n=62)$ or Past Inequality $(29 \%, n=51)$. An additional $17 \%$ of children $(n=30)$ referenced Status Quo, $16 \%(n=28)$ referenced Personal Preferences, and only 3\% $(n=6)$ were unable to give a justification for their allocation.

First, in order to test our hypotheses regarding age-related changes in children's reasoning for their decisions (H3), we conducted a 2 (Age: 5-6 years, 10-11 years) x 2 (Allocation: Rectify, Perpetuate) x 5 (Justification) chi square test of independence. The overall test was significant, $\chi^{2}(4, N=177)=30.89, p<.001$. Follow-up z-tests with Bonferroni correction for multiple comparisons indicated that older children referenced Past Inequality (e.g., “They didn't have more before, so I'm giving them more now") more than younger children. Interestingly, older children also referenced Equality more than younger children. Additionally, older children were less likely than younger children to reference Personal Preferences. References to Status Quo (e.g., "I noticed that they always get more and they always get less") did not differ significantly by age. All differences reported were significant at $p<.05$.

Further, age-related changes in children's reasoning were significant among children who allocated more resources to the disadvantaged group, $\chi^{2}(4, N=114)=19.48, p<.001$, and among children who allocated more resources to the advantaged group, $\chi^{2}(3, N=63)=12.35, p$ $=.001$. Among children who allocated more resources to the disadvantaged group, older children referenced Equality (e.g., "Because then it would be the closest to even and it would be fair") 
more than younger children, and referenced Personal Preferences less frequently than younger children. References to Past Inequality and Status Quo did not differ significantly by age among children who allocated more resources to the disadvantaged group. All differences reported were significant at $p<.05$; see Table 2 for all proportions.

Among children who allocated more resources to the advantaged group, older children referenced Personal Preferences less frequently than younger children. References to Equality and Status Quo did not differ significantly by age among children who allocated more resources to the advantaged group. No children who allocated more resources to the advantaged group referenced Past Inequality. All differences reported were significant at $p<.05$; see Table 2 for all proportions.

Table 2 .

Children's Reasoning for their Resource Allocation Decision, by Age Group and Allocation Decision

\begin{tabular}{|c|c|c|c|c|c|c|c|c|}
\hline & \multicolumn{4}{|c|}{ Allocation: More to Disadvantaged Group } & \multicolumn{4}{|c|}{ Allocation: More to Advantaged Group } \\
\hline & \multicolumn{2}{|c|}{$\begin{array}{l}\text { Younger Children } \\
\text { (5-6 Years) }\end{array}$} & \multicolumn{2}{|c|}{$\begin{array}{l}\text { Older Children } \\
\text { (10-11 Years) }\end{array}$} & \multicolumn{2}{|c|}{$\begin{array}{l}\text { Younger Children } \\
\text { (5-6 Years) }\end{array}$} & \multicolumn{2}{|c|}{$\begin{array}{l}\text { Older Children } \\
\text { (10-11 Years) }\end{array}$} \\
\hline & Proportion & $n$ & Proportion & $n$ & Proportion & $n$ & Proportion & $n$ \\
\hline $\begin{array}{l}\text { Past } \\
\text { Inequality }\end{array}$ & .36 & 18 & .52 & 33 & 0 & 0 & 0 & 0 \\
\hline Equality & $.20^{a}$ & 10 & $.39^{a}$ & 25 & .33 & 12 & .56 & 15 \\
\hline Status Quo & .12 & 6 & .05 & 3 & .28 & 10 & .41 & 11 \\
\hline $\begin{array}{l}\text { Personal } \\
\text { Preferences }\end{array}$ & $.26^{b}$ & 13 & $.03^{b}$ & 2 & $.36^{c}$ & 13 & $0^{c}$ & 0 \\
\hline Other & .06 & 3 & .02 & 1 & .03 & 1 & .04 & 1 \\
\hline
\end{tabular}

Note. $a, b$, and $c$ denote column proportions that differ significantly from each other at $p<.05$. 
Children's justifications for their resource allocation decision did not vary significantly by race, $\chi^{2}(4, N=177)=2.01, p=.73$, or by whether the participant had seen their ingroup or the outgroup receiving fewer supplies, $\chi^{2}(4, N=177)=1.18, p=.88$. Additionally, a 2 (Age: 56 years, 10-11 years) x 2 (Group Received Fewer Supplies: Ingroup, Outgroup) x 5 (Justification) chi square test of independence revealed no significant differences in children's justifications at 5-6 years, $\chi^{2}(4, N=86)=1.84, p=.77$, or at 10-11 years, $\chi^{2}(4, N=91)=2.43$, $p=.66$, based on whether children had seen their racial ingroup or the outgroup receiving fewer supplies.

In short, older children were more likely than younger children (overall) to reference the importance of correcting past inequalities by providing more resources to the disadvantaged group, and were less likely to reference their own personal preferences when explaining their resource allocation decision. Further, paralleling their reasoning about the wrongfulness of inequality (above), older children who rectified the inequality were more likely to reference the importance of ensuing equal access to school supplies than were younger children who rectified the inequality. Thus, age-related differences in children's decisions to rectify the inequality (regardless of whether their ingroup or the outgroup had received fewer resources) mapped on to age-related increases in reasoning about groups' past history of unequal access to resources and the importance of ensuring equal access.

\subsection{Evaluations of the Perpetuate and Rectify Allocation Strategies}

When evaluating potential allocation strategies, the majority of children (77\%) negatively evaluated ("not okay"/"really not okay") the strategy of giving more supplies to a school "because they always got more before" (perpetuate) with $23 \%$ of children evaluating it positively (“okay"/"really okay"). The majority of children (70\%) positively evaluated the strategy of 
giving more supplies to a school "because they always got less before" (rectify), with 30\% of children evaluating it negatively.

To test our hypotheses regarding differences in children's evaluations of these allocation strategies by age and by which group they had seen receiving fewer resources (H1 and H2), we conducted a 2 (Age: 5-6 years, 10-11 years) x 2 (Race: African-American, European-American), x 2 (Group Received Fewer Supplies: Ingroup, Outgroup) x 2 (Strategy: Perpetuate, Rectify) ANOVA with repeated measures on the last factor. This revealed a main effect for Strategy, $F(1,173)=111.74 p<.001, \eta_{\mathrm{p}}{ }^{2}=.39$; children evaluated the Rectify strategy $(M=2.88, S D=$ $.99)$ more positively than the Perpetuate strategy $(M=1.83, S D=.94)$.

This main effect was explained by a Strategy x Age interaction, $F(1,173)=13.03 p<$ $.001, \eta_{\mathrm{p}}{ }^{2}=.07$, which was followed up using pairwise comparisons with Bonferroni correction for multiple comparisons. While children at both ages evaluated the Rectify strategy more positively than the Perpetuate strategy (both $p s<.001$ ), older children evaluated the Perpetuate strategy more negatively $(M=1.52, S D=.72)$ than did younger children $(M=2.15, S D=1.02)$, $p<.001$. Evaluations of the Rectify strategy did not differ significantly with age; $M_{\text {Younger }}=2.84$ $S D=1.09, M_{\text {Older }}=2.93, S D=.88, p=.57$.

Next, we conducted chi square tests for the same hypotheses (H1 and H2) with children's evaluations dichotomized to "not okay" versus "okay". This enabled us to test for differences in the proportion of children evaluating each strategy to be acceptable (“okay" or "really okay") versus unacceptable ("not okay" or "really not okay") by age and by which group had received fewer supplies (ingroup or outgroup). McNemar (within-subjects) models replicated the main effect for Strategy reported in the ANOVA above; participants more frequently evaluated the Rectify strategy positively $(71 \%)$ than the Perpetuate strategy $(23 \%), p<.001$. Also parallel to 
the ANOVA above, a smaller proportion of older children (9\%) than younger children (38\%) evaluated the perpetuate strategy to be "okay", $\chi^{2}(1, N=181)=21.34, p<.001$. Evaluations of the Rectify strategy did not change significantly with age, $\chi^{2}(1, N=181)=1.42, p=.23 ; 67 \%$ of younger children and $75 \%$ of older children evaluated this strategy positively. No additional significant main or interaction effects were found for which group was disadvantaged (ingroup or outgroup). In order to remain consistent with the visual presentation of all other results reported in this paper, Figure 3 displays this effect split by age group and condition.

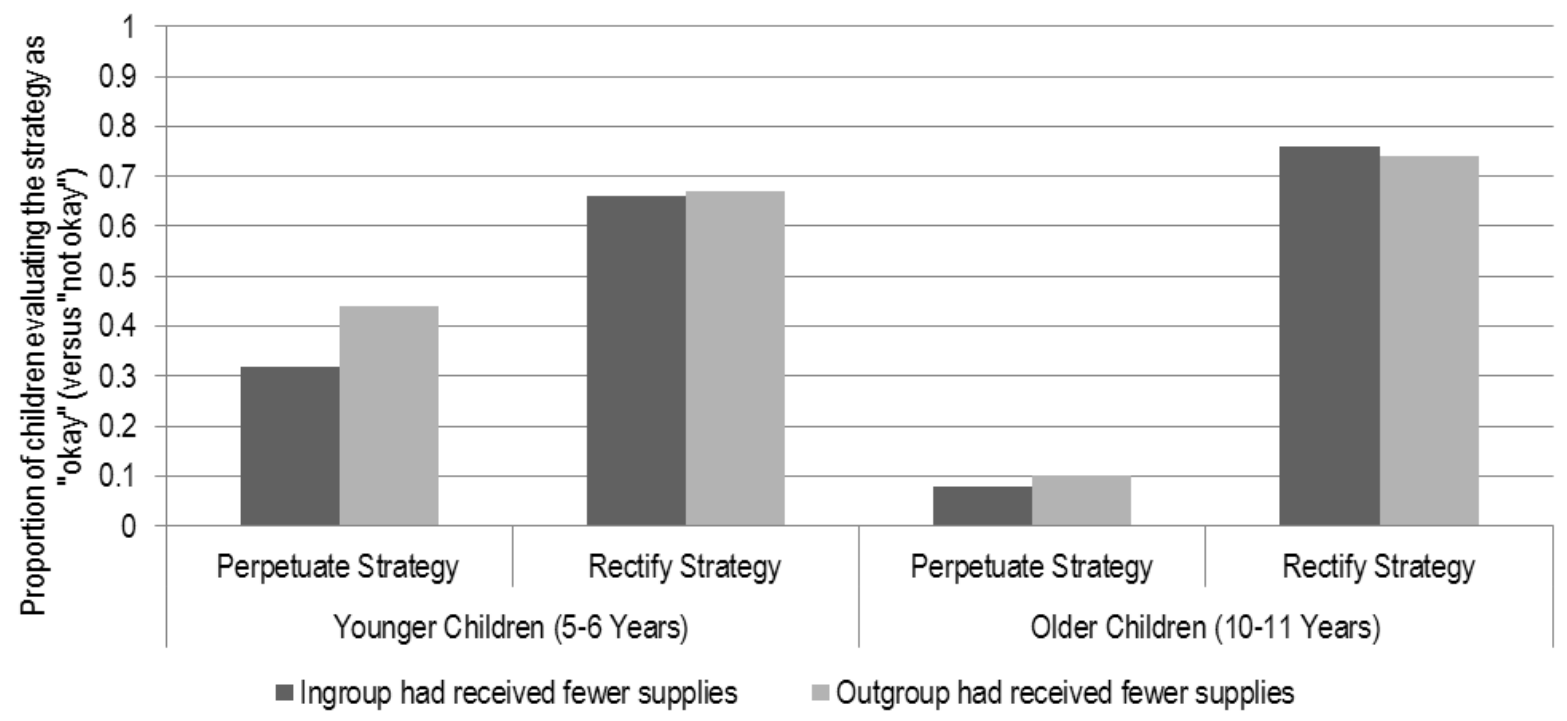

Figure 3. Proportion of children who judged each strategy negatively, by age and by which group they had observed receiving fewer supplies.

Together, these findings on children's evaluations of two allocation strategies revealed that, in line with their allocation decisions (above), children judged the Rectify strategy more positively than the Perpetuate strategy, and evaluations of the Perpetuate strategy became more negative with age. Interestingly, however, children's evaluations of these two allocation 
strategies did not differ significantly based on which group they witnessed receiving fewer resources. Supporting recent research examining the integration of children's judgments, reasoning, and behavior with age, these results suggest that children were able to identify and positively evaluate a corrective allocation strategy (when the outgroup was disadvantaged) at an earlier age than they were able to consistently enact this strategy themselves. Further discussion of these findings is provided in the following section.

\section{Conclusions and Discussion}

In most societies, opportunities and resources are not evenly distributed between groups. The question of how to address social inequalities, however, is complex. In this study, we investigated the developmental origins of the ability to consider social inequalities in the context of intergroup resource disparities. We measured children's judgments, reasoning, and behavior in response to an inequality of educational resources between peers of different racial backgrounds --African-American and European-American-- revealing new findings about the role of intergroup biases as well as moral conceptions of fairness in response to social inequalities.

The novel findings of this study revealed that young children (5-6 year-olds) who witnessed their racial ingroup receiving fewer school supplies than an outgroup evaluated the inequality negatively, and looked to rectify it. When faced with an inequality that put the outgroup at a disadvantage, however, older, but not younger children, rejected the inequality. That is, 10-11 year-olds, but not 5-6 year-olds, generalized their negative responses to the school supply inequality to contexts in which the outgroup was disadvantaged, demonstrating an increasing willingness to take action to ensure fair access to important resources.

Understanding the origins of behaviors that challenge the legitimacy of resource inequalities between groups is essential to creating a more just society. Drawing on the 
framework of the social reasoning developmental (SRD) model (Killen et al., 2015; Rutland et al., 2010), findings from this study highlighted changes in children's concern for fair and equal treatment of others and awareness of group concerns, pinpointing how children's responses to an intergroup inequality of school supplies change with age. A next step for research would be to adapt the methods used in the present study for adolescent and adult samples in order to determine how individuals think about social inequalities across the lifespan.

This study makes three unique contributions to the literature on resource allocation, social decision-making, and moral judgment. First, while considerable previous research has focused on European-American children's preferential resource allocation to their racial ingroup, the current study directly compared African-American and European-American children's responses to an intergroup inequality. Supporting the SRD model, our findings advance an understanding of how children integrate their moral judgments about the obligation to treat others fairly with their social preferences for their ingroup (Killen et al., 2015; Rutland et al., 2010). Second, by measuring children's reasoning for their judgments and decisions, findings from our study point to potential underlying mechanisms supporting changes in the capacity to evaluate and critique unfair allocation norms and consider how best to respond to resource disparities. Third, whereas most previous research in this area has focused on the allocation of desirable resources that may not directly bear on recipients' wellbeing (such as stickers or candy), the current study examined children's responses to an inequality of educational supplies, an important resource that when, when distributed unequally, has an especially detrimental impact on disadvantaged groups. Our findings demonstrated that children's increasing recognition of the importance of distributing such resources fairly. This is illustrated most clearly 
in children's reasoning for their decisions, as children increasingly referenced the importance of equality and equal access to school supplies with age.

\subsection{Weighing Moral and Social Concerns: Age-Related Changes}

Resource allocation decisions in intergroup contexts can invoke issues of prejudice, discrimination, and bias. However, when there is a history of unequal resource allocation between groups, taking group membership into account is important for ensuring distributive justice and fair access to resources. That is, consideration of group membership is essential for achieving a fair allocation. Extending recent work drawing on the SRD model (e.g., Cooley \& Killen, 2015; Mulvey et al., 2014), we aimed to examine how children would weigh moral concerns about fairness with group affiliations when responding to an intergroup inequality of educational resources.

We found that young children's responses differed depending on whether they witnessed their racial ingroup or an outgroup at a disadvantage. Specifically, 5-6 year-olds who witnessed their racial ingroup at a disadvantage judged the inequality to be unacceptable and rectified it by giving more supplies to a new school representing the ingroup. However, 5-6 year-olds who witnessed the outgroup at a disadvantage did not consistently demonstrate the same types of judgments and allocations. This indicates that younger children may be struggling with these kinds of decisions, unsure of what would be the right course of action, and drawing on different kinds of reasons (e.g., thinking about the past inequality, but also thinking about their own personal preferences) to guide their decision.

Older children (10-11 year-olds), by contrast, increasingly justified their decisions in terms of the importance of ensuring equal access to school supplies. Specifically, 10-11 yearolds judged the inequality to be unacceptable, rectified it by giving more supplies to a new 
school representing the group that they had seen receiving fewer supplies, and evaluated another person's decision to perpetuate the inequality as unacceptable and rectify the inequality as acceptable, regardless of which racial group they had seen receiving fewer school supplies. This implies that, unlike younger children, older children's judgments, actions, and reasoning reflected a generalizable and unified concern for ensuring fair access to school supplies that took precedence over social preferences for the ingroup.

Importantly, younger children did not always evidence ingroup bias by allocating more resources to members of their racial ingroup (e.g., Renno \& Shutts, 2015), nor did they always perpetuate the inequality by allocating more resources to the advantaged group (e.g., Olson et al., 2011). Rather, younger children's responses to inequality in this context were similar to recent findings indicating that young children judge it more obligatory and more emotionally gratifying to help racial ingroup members than racial outgroup members (Weller \& Lagattuta, 2013), and are more likely to demonstrate racial biases in ambiguous social contexts where more than one response may seem appropriate (McGlothlin \& Killen, 2006). Younger children privileged the needs of their own racial group (judging the inequality negatively and correcting it) while demonstrating more mixed responses toward the needs of an outgroup.

The findings demonstrating age-related changes in children's responses to inequality support the predictions of the SRD model, in that older children were able to use their knowledge about prior unfair intergroup relations (i.e., unequal resource distributions) to promote fair access to resources. Notably, these age-related changes were found in a context in which the inequality (of school supplies) would have an especially detrimental impact on the disadvantaged group. Similar to recent findings indicating that older children help needy ingroup and outgroup members equally (Sierksma, Thijs, \& Verkuyten, 2014), older children's reasoning in this study 
demonstrated their moral concerns for ensuring fair access to resources. These findings reveal an emerging concern for equal access not frequently observed in other resource allocation paradigms in which observation of an inequality between groups can lead children to perpetuate it (e.g., Horwitz et al., 2014; Li et al., 2014).

Few studies include behavioral, judgment, and reasoning measures in the same experimental paradigm. These findings with younger participants in particular reveal the importance of a multi-method approach to understanding children's developing consideration of fairness and group membership concerns in allocation contexts. The first (or earliest) evidence of children's ability to use information about unfair intergroup relations to promote fair allocation between groups emerged in their evaluations of strategies proposed by others, rather than their own behavioral decisions. That is, while their own allocations reflected a form of differential distribution privileging the needs of their ingroup, younger children were able to identify and positively evaluate a corrective allocation strategy (the 'rectify' strategy) when the outgroup was disadvantaged. They evaluated the 'rectify' strategy (for the outgroup) positively even though they did not consistently enact this strategy themselves.

Interestingly, related research on young children's judgments and allocations in response to inequalities on the individual level has also revealed similar age-related changes in children's developing allocations and judgments of potential allocation strategies (Rizzo et al., 2016). Thus, these findings suggest that effectively coordinating fairness and group concerns to determine the best course of action emerges later in development than children's ability to recognize and endorse a positive allocation strategy (rectifying an inequality). As both components of children's responses are necessary for understanding how resource allocation decisions bear on social inequalities, these findings suggest a promising area for future research. 


\subsection{Role of Group Membership}

We included children of both African-American and European-American background in this study in order to test our hypotheses regarding ingroup bias in young children's responses with a balanced sample. Related research indicates that older African-American children and adolescents are more aware of discrimination than their European-American peers (Brown et al., 2011; McKown \& Weinstein, 2003; McKown, 2004), suggesting that this group may also be more likely to correct a discriminatory resource inequality. In the current study, however, we did not find differences in children's judgments, allocations, or reasoning based on participant race, in line with other studies reporting no significant racial differences in children's ability to detect discrimination (Brown, 2006; McKown \& Strambler, 2009).

It is possible that, in this context, what may be more relevant than children's racial group membership are personal experiences with differential treatment as a result of group membership. Many adolescents of African-American background report increasing personal experiences with discrimination from teachers, peers, and strangers, with reports ranging from wrongful discipline in school to being hassled by store clerks to teasing and online harassment (Fisher, Wallace, \& Fenton, 2000; Rivas-Drake, Hughes, \& Way, 2009). It may be that, later in development (i.e., with a sample of children older than the participants in this study), increasing personal experiences with others' biases would be associated with greater recognition of discriminatory resource allocation, and potentially a greater tendency to rectify resource inequalities for African-American adolescents relative to European-American adolescents. This possibility remains open for future research with older participant samples.

Although differences by participant race did not emerge for this sample of 5-6 and 10-11 year-olds, the race of the target group was clearly a salient variable for children's responses. 
What was important, in this context, was the interaction of participant race and the race of the group that children witnessed receiving fewer school supplies. As described above, differential responses to inequality based on ingroup bias were prevalent among both African-American and European-American 5-6 year-olds.

\subsection{Future Directions}

Clearly there are contexts in which individuals do not rectify social inequalities. Our findings regarding young children's decisions revealed one of the factors (ingroup bias) that may inhibit this response to inequality. Additionally, some children, even at 10-11 years, reasoned about the resource inequality in a way that reflected misattributions for its cause (i.e., assuming that one group had more supplies than the other because they needed more). Their justifications revealed that this subset of children perceived the inequality to be legitimate rather than unfair. In fact, little is known about how adolescents and young adults would respond to the type of scenario investigated in this study, and further research with different (older) participant populations would be important. Moreover, there are ways in which the paradigm used in the present study could be expanded, such as determining how individuals respond to a lack of access to opportunities rather than to concrete resources, whether children respond similarly to inequalities based on other types of group membership (e.g., gender), and whether some children demonstrate consistent negative responses to inequality across different measures (e.g., judgments and allocations) whereas others are less consistent in their responses.

In particular, there are many other resources that, when unequally distributed, may prompt different types of responses regarding rectifying inequality. For instance, it may be that, with institutions that directly address others' welfare, such as hospitals, there would be a stronger response to rectify inequalities. With resources that are more desirable but less necessary for 
recipient wellbeing, responses may also differ based on children's expectations for how their group would prefer them to allocate (DeJesus, Rhodes, \& Kinzler, 2014; Elenbaas \& Killen, 2016; McGuire, Rutland, \& Nesdale, 2015).

More research is needed in order to directly compare children's responses to intergroup inequalities of different types of resources. Future research in this area could compare children's judgments, reasoning, and behavior in contexts where educational resources (or other goods that are important for recipients' welfare) are unequally distributed versus contexts in which less necessary items (e.g., stickers) are unequally distributed in order to provide a more complete picture of how children respond to "ingroup" and "outgroup" disadvantage with regard to different types of resources. Resource value (Shaw \& Olson, 2013), desirability (Blake \& Rand, 2010), or rarity (Chernyak \& Sobel, 2015) may also contribute to children's allocation decisions. The age-related changes revealed in the current study suggest that older children and early adolescents may be an ideal population for this type of extension of the current paradigm.

Thus, in addition to highlighting the importance of using multiple measures to understand children's responses to inequality, these findings point to important areas for future research. Understanding the developmental origins of behavior, judgments and reasoning about social inequalities in the context of resource distribution provides a window into areas for intervention, and for facilitating social equality, with the goal of creating a society of equals. 


\section{References}

Abrams, D., \& Rutland, A. (2008). The development of subjective group dynamics. In S. R. Levy \& M. Killen (Eds.), Intergroup attitudes and relations in childhood through adulthood. (pp. 47-65). New York, NY: Oxford University Press.

Appiah, K. A. (2005). The Ethics of Identity. Princeton, NJ: Princeton University Press.

Baumard, N., Mascaro, O., \& Chevallier, C. (2012). Preschoolers are able to take merit into account when distributing goods. Developmental Psychology, 48, 492-498. doi:10.1037/a0026598

Benozio, A., \& Diesendruck, G. (2015). Parochialism in preschool boys' resource allocation. Evolution and Human Behavior, 36, 256-264. doi:10.1016/j.evolhumbehav.2014.12.002

Blake, P. R., \& McAuliffe, K. (2011). “I had so much it didn't seem fair”: Eight-year-olds reject two forms of inequity. Cognition, 120, 215-224. doi:10.1016/j.cognition.2011.04.006

Blake, P. R., McAuliffe, K., Corbit, J., Callaghan, T. C., Barry, O., Bowie, A., ... Warneken, F. (2015). The ontogeny of fairness in seven societies. Nature. doi:10.1038/nature15703

Blake, P. R., \& Rand, D. G. (2010). Currency value moderates equity preference among young children. Evolution and Human Behavior, 31, 210-218.

doi:10.1016/j.evolhumbehav.2009.06.012

Brown, C. S. (2006). Bias at school: Perceptions of racial/ethnic discrimination among Latino and European American children. Cognitive Development, 21, 401-419. doi:10.1016/j.cogdev.2006.06.006

Brown, C. S., Alabi, B. O., Huynh, V. W., \& Masten, C. L. (2011). Ethnicity and gender in late childhood and early adolescence: Group identity and awareness of bias. Developmental Psychology, 47, 463-471. doi:10.1037/a0021819 
Chernyak, N., \& Sobel, D. M. (2015). Equal but not always fair: Value-laden sharing in preschool-aged children. Social Development. doi:10.1111/sode.12136

Cooley, S., \& Killen, M. (2015). Children's evaluations of resource allocation in the context of group norms. Developmental Psychology, 51, 554-563. doi:10.1037/a0038796

DeJesus, J. M., Rhodes, M., \& Kinzler, K. D. (2014). Evaluations versus expectations: Children's divergent beliefs about resource distribution. Cognitive Science, 38, 178-93. doi:10.1111/cogs.12093

Duncan, G. J., \& Murnane, R. J. (Eds.). (2011). Whither opportunity? Rising inequality, schools, and children's life chances. New York, NY: Russell Sage Foundation.

Dunham, Y., Baron, A. S., \& Carey, S. (2011). Consequences of "minimal” group affiliations in children. Child Development, 82, 793-811. doi:10.1111/j.1467-8624.2011.01577.x

Elenbaas, L., \& Killen, M. (2016). How do young children expect others to address resource inequalities? Journal of Experimental Child Psychology, 150, 72-86. doi:10.1016/j.jecp.2016.05.002

Fehr, E., Bernhard, H., \& Rockenbach, B. (2008). Egalitarianism in young children. Nature, 454, 1079-1083. doi:10.1038/nature07155

Fisher, C. B., Wallace, S. A., \& Fenton, R. E. (2000). Discrimination distress during adolescence. Yournal of Youth and Adolescence, 26, 679-695. doi:10.1023/A:1026455906512

Gummerum, M., Takezawa, M., \& Keller, M. (2009). The influence of social category and reciprocity on adults' and children's altruistic behavior. Evolutionary Psychology, 7, 295316. doi:10.1177/147470490900700212

Helwig, C. C., \& Jasiobedzka, U. (2001). The relation between law and morality: Children's 
reasoning about socially beneficial and unjust laws. Child Development, 72, 1382-93. doi:10.1111/1467-8624.00354

Horn, S. S. (2003). Adolescents' reasoning about exclusion from social groups. Developmental Psychology, 39, 71-84. doi:10.1037/0012-1649.39.1.71

Horwitz, S. R., Shutts, K., \& Olson, K. R. (2014). Social class differences produce social group preferences. Developmental Science, 17, 991-1002. doi:10.1111/desc.12181

Jordan, J. J., McAuliffe, K., \& Warneken, F. (2014). Development of in-group favoritism in children's third-party punishment of selfishness. Proceedings of the National Academy of Sciences of the United States of America, 111, 12710-12715. doi:10.1073/pnas.1402280111

Kienbaum, J., \& Wilkening, F. (2009). Children's and adolescents' intuitive judgements about distributive justice: Integrating need, effort, and luck. European Journal of Developmental Psychology, 6, 481-498. doi:10.1080/17405620701497299

Killen, M., Elenbaas, L., Rizzo, M. T., \& Rutland, A. (2016). The role of group processes in social exclusion and resource allocation decisions. In A. Rutland, D. Nesdale, \& C. Spears Brown (Eds.), Handbook of group processes in children and adolescents. New York, NY: Wiley-Blackwell.

Killen, M., Elenbaas, L., \& Rutland, A. (2015). Balancing the fair treatment of others while preserving group identity and autonomy. Human Development, 58, 253-272. doi:10.1159/000444151

Killen, M., Lee-Kim, J., McGlothlin, H., \& Stangor, C. (2002). How children and adolescents evaluate gender and racial exclusion. Monographs of the Society for Research in Child Development, 67. doi:10.1111/1540-5834.00218

Killen, M., \& Smetana, J. G. (2015). Origins and development of morality. In M. E. Lamb (Ed.), 
Handbook of child psychology and developmental science, Vol. 3 (7th ed., pp. 701-749). New York, NY: Wiley-Blackwell.

Levy, S. R., West, T. L., \& Ramirez, L. (2005). Lay theories and intergroup relations: A socialdevelopmental perspective. European Review of Social Psychology, 16, 189-220. doi:10.1080/10463280500397234

Li, V., Spitzer, B., \& Olson, K. R. (2014). Preschoolers reduce inequality while favoring individuals with more. Child Development, 85, 1123-33. doi:10.1111/cdev.12198

McGillicuddy-De Lisi, A. V, Daly, M., \& Neal, A. (2006). Children's distributive justice judgments: Aversive racism in Euro-American children? Child Development, 77, 10631080. doi:10.1111/j.1467-8624.2006.00919.x

McGlothlin, H., \& Killen, M. (2006). Intergroup attitudes of European American children attending ethnically homogeneous schools. Child Development, 77, 1375-1386. doi:10.1111/j.1467-8624.2006.00941.x

McGuire, L., Rutland, A., \& Nesdale, D. (2015). Peer group norms and accountability moderate the effect of school norms on children's intergroup attitudes. Child Development, 86, 12901297. doi:10.1111/cdev.12388

McKown, C. (2004). Age and ethnic variation in children's thinking about the nature of racism. Journal of Applied Developmental Psychology, 25, 597-617. doi:10.1016/j.appdev.2004.08.001

McKown, C., \& Strambler, M. J. (2009). Developmental antecedents and social and academic consequences of stereotype-consciousness in middle childhood. Child Development, 80 , 1643-1659. doi:10.1111/j.1467-8624.2009.01359.x

McKown, C., \& Weinstein, R. S. (2003). The development and consequences of stereotype 
consciousness in middle childhood. Child Development, 74, 498-515. doi:10.1111/14678624.7402012

Melis, A. P., Altrichter, K., \& Tomasello, M. (2013). Allocation of resources to collaborators and free-riders in 3-year-olds. Journal of Experimental Child Psychology. doi:10.1016/j.jecp.2012.08.006

Moore, C. (2009). Fairness in children's resource allocation depends on the recipient. Psychological Science, 20, 944-948. doi:10.1111/j.1467-9280.2009.02378.x

Mulvey, K. L., Hitti, A., Rutland, A., Abrams, D., \& Killen, M. (2014). When do children dislike ingroup members? Resource allocation from individual and group perspectives. Journal of Social Issues, 70, 29-46. doi:10.1111/josi.12045

Nesdale, D. (2004). Social identity processes and children's ethnic prejudice. In M. Bennett \& F. Sani (Eds.), The development of the social self. (pp. 219-245). New York, NY: Psychology Press. doi:10.4324/9780203391099_chapter_8

Nussbaum, M. (2001). Women and human development: The capabilities approach. New York, NY: Cambridge University Press.

Olson, K. R., Dweck, C. S., Spelke, E. S., \& Banaji, M. R. (2011). Children's responses to group-based inequalities: Perpetuation and rectification. Social Cognition, 29, 270-287. doi:10.1521/soco.2011.29.3.270

Paulus, M. (2014). The early origins of human charity: Developmental changes in preschoolers' sharing with poor and wealthy individuals. Frontiers in Psychology, 5, 1-9. doi:10.3389/fpsyg.2014.00344

Peterson-Badali, M., Morine, S. L., Ruck, M. D., \& Slonim, N. (2004). Predictors of maternal and early adolescent attitudes toward children's nurturance and self-determination rights. 
Journal of Early Adolescence, 24, 159-179. doi:10.1177/0272431603262667

Renno, M. P., \& Shutts, K. (2015). Children's social category-based giving and its correlates: Expectations and preferences. Developmental Psychology, 51, 533-543. doi:10.1037/a0038819

Rivas-Drake, D., Hughes, D., \& Way, N. (2009). A preliminary analysis of associations among ethnic racial socialization, ethnic discrimination, and ethnic identity among urban sixth graders. Journal of Research on Adolescence, 19, 558-584. doi:10.1111/j.15327795.2009.00607.x

Rizzo, M. T., Elenbaas, L., Cooley, S., \& Killen, M. (2016). Children’s recognition of fairness and others' welfare in a resource allocation task: Age related changes. Developmental Psychology. doi:10.1037/dev0000134

Rizzo, M. T., \& Killen, M. (2016). Children's understanding of equity in the context of inequality. British Journal of Developmental Psychology. doi:10.1111/bjdp.12150

Rutland, A., Killen, M., \& Abrams, D. (2010). A new social-cognitive developmental perspective on prejudice: The interplay between morality and group identity. Perspectives on Psychological Science, 5, 279-291. doi:10.1177/1745691610369468

Schmidt, M. F. H., Svetlova, M., Johe, J., \& Tomasello, M. (2016). Children's developing understanding of legitimate reasons for allocating resources unequally. Cognitive Development, 37, 42-52. doi:10.1016/j.cogdev.2015.11.001

Sen, A. K. (2009). The Idea of Justice. Cambridge, MA: Harvard University Press.

Shaw, A., \& Olson, K. R. (2012). Children discard a resource to avoid inequity. Journal of Experimental Psychology, 141, 382-395. doi:10.1037/a0025907

Shaw, A., \& Olson, K. R. (2013). All inequality is not equal: Children correct inequalities using 
resource value. Frontiers in Psychology, 4, 393. doi:10.3389/fpsyg.2013.00393

Sierksma, J., Thijs, J., \& Verkuyten, M. (2014). Children's intergroup helping: The role of empathy and peer group norms. Journal of Experimental Child Psychology, 126, 369-83. doi:10.1016/j.jecp.2014.06.002

Smetana, J. G., Jambon, M., \& Ball, C. (2014). The social domain approach to children's moral and social judgments. In M. Killen \& J. G. Smetana (Eds.), Handbook of moral development (2nd ed., pp. 23-45). New York, NY: Psychology Press.

Turiel, E. (2006). The development of morality. In N. Eisenberg, W. Damon, \& R. M. Lerner (Eds.), Handbook of child psychology: Vol. 3. Social, emotional, and personality development (6th ed., pp. 863-932). Hoboken, NJ: John Wiley \& Sons Inc.

Verkuyten, M. (2007). Ethnic in-group favoritism among minority and majority groups: Testing the self-esteem hypothesis among preadolescents. Journal of Applied Social Psychology, 37, 486-500. doi:10.1111/j.1559-1816.2007.00170.x

Wainryb, C., Smetana, J. G., \& Turiel, E. (2008). Social development, social inequalities, and social justice. New York, NY: Taylor \& Francis Group/Lawrence Erlbaum Associates.

Warneken, F., Lohse, K., Melis, A. P., \& Tomasello, M. (2011). Young children share the spoils after collaboration. Psychological Science, 22, 267-273. doi:10.1177/0956797610395392

Weller, D., \& Lagattuta, K. H. (2013). Helping the in-group feels better: Children's judgments and emotion attributions in response to prosocial dilemmas. Child Development, 84, 25368. doi:10.1111/j.1467-8624.2012.01837.x 